\title{
Should the high-flow nasal oxygen therapy be used or avoided in COVID-19?
}

\author{
Ting-Ting Zhang, Bing Dai, Wei Wang \\ Department of Respiratory and Critical Care Medicine, The First Hospital of China Medical University, \\ Shenyang 110001, Liaoning Province, China
}

Since the beginning of December 2019, more than 5 million people around the world have been infected with the epidemic of coronavirus disease 2019 (COVID-19). Its common symptoms include dyspnea and hypoxemia; but the disease progresses very fast in severe cases and may lead to acute respiratory distress syndrome (ARDS). Though high-flow nasal cannula (HFNC) is used for oxygen delivery in patients with acute hypoxemic respiratory failure, including pneumonia, its use in COVID-19 remains controversial.

Considering that HFNO may increase the risk of virus transmission while the clinical benefits are not significant, and a lack of oxygen and equipment resources, there is a trend to avoid using HFNC in some hospitals. Also, a joint guidance drafted by the experts of Intensive Care and Intensive Care Medicine Societies, Association of Anaesthetists, and Royal College of Anaesthetists states that highflow nasal oxygen or similar devices should be avoided. ${ }^{[1]}$ While guidelines from other organizations or societies worldwide, such as the World Health Organization (WHO) ${ }^{[2]}$ the Respiratory Care Committee of the Chinese Thoracic Society, ${ }^{[3]}$ the Italian Thoracic Society, ${ }^{[4]}$ the Australian and New Zealand Intensive Care Society, ${ }^{[5]}$ and a joint press statement from the German anesthesia, intensive care, and emergency medicine societies, ${ }^{[6]}$ as well as the joint guidelines made by the European Society of Intensive Care Medicine and The Society of Critical Care Medicine, ${ }^{[7]}$ all recommend HFNC as a therapy for hypoxemic respiratory failure caused by COVID-19.

There is no evidence that those exposed to HFNO have an increased risk of aerosol transmission and virus infection. Hui et al. insisted that furthest distance of exhaled air dispersion during HFNC therapy and administration of continuous positive airway pressure (CPAP) was limited when used correctly. In vitro studies. ${ }^{[8]}$ Loose connection between the cannula and the interface tube may lead to a maximum distance leakage up to $620 \mathrm{~mm}$ in the lateral plane. By using bacterial or yeast solution aerosols as markers, some researchers evaluated the impact of HFNC on environmental pollution and found that the aerosol diffusion distance is also relatively limited..$^{[9]}$ By comparison, there is no significant difference in aerosol diffusion distance between HFNC and conventional oxygen therapy. HFNC has not been found to increase the risk of virus transmission or nosocomial infection during the treatment of diseases such as severe acute respiratory syndrome (SARS) and influenza A (H1N1) outbreaks. ${ }^{[10]}$

Although the above research findings may give us tremendous words of encouragement, HFNC should still be regarded as a high-risk operation that may increase the risk of virus transmission. Make sure the isolation of patient and personal protection of medical staff are strictly implemented. A negative pressure room is 
preferred for patients to receive HFNC since it may cause the generation of aerosol. Also, it should be undertaken in a single room if the negative pressure rooms are small. Unnecessary patient interactions with the medical staff should be avoided or it should occur at a distance where possible when necessary. Other measures, such as wearing a superimposed facemask (such as surgical facemask and oxygen mask), closing the mouth and breathing through the nose during HFNC, and wearing the nasal catheter correctly to avoid loose connections may greatly reduce the risk of virus transmission and should be used as much as possible.

A recent meta-analysis stated that no difference in mortality was observed in patients treated with HFNO when compared with those treated with conventional oxygen therapy, but the use of HFNC resulted in a decreased requirement for tracheal intubation and a lower risk of escalation of oxygen therapy. ${ }^{[1]}$ During the COVID-19 pandemic, reduction in the need for intubation is an important finding since it will be propitious for solving problems such as limited availability of medical resources such as critical care beds and ventilators and it will avoid a greater risk of virus transmission caused by endotracheal intubation. As we all know, HFNC is not suitable for all COVID-19 patients with severe hypoxemia. The WHO recommends that HFNC should only be used in particular patients with hypoxemic respiratory failure and be avoided in patients with acidemia, worsening hypercapnia, respiratory fatigue, hemodynamic instability, or those with altered mental status. ${ }^{[2]}$ It insists that patients treated with HFNC should be monitored closely. Patients who require vasopressor support and who are unable to rapidly relieve respiratory rate and chest/abdomen conflict breathing may be at a potentially high risk of HFNO failure. When the patient's condition deteriorates rapidly or does not improve after a short period of time (usually 1 hour), tracheal intubation should be performed in time by an experienced healthcare provider.

During the COVID-19 pandemic, some centralized isolation treatment units have been temporarily constructed and the oxygen supply may be limited in them. Some units suggest to avoid using HFNC to save oxygen for the need of other ventilators, since it is more oxygen consuming than other methods of respiratory support. In clinical practice, the scope of use of HFNC should be evaluated according to the robustness of the oxygen supply of the clinical unit and the availability of HFNC equipment.

To sum up, the use of HFNC for patients with COVID-19 must balance the clinical benefit of the intervention against the risks of nosocomial spread. It is dogmatic to absolutely avoid applying HFNC. HFNC may be an appropriate method of oxygen support for many COVID-9 patients with acute hypoxemic respiratory failure, and isolation of patients and personal protection of medical staff should be strictly implemented and close monitoring of patients should be carried out. Tracheal intubation should be performed in the event of an acute deterioration or failure to improve after a short trial.

\section{Conflict of Interest}

There are no conflicts of interest.

\section{REFERENCES}

1. Faculty of Intensive Care Medicine I C S, Association of Anaesthetists and Royal College of Anaesthetists. Critical care preparation and management in the COVID-19 pandemic. May 17, 2020. Accessed on Jun 1, 2020. Available from: https://icmanaesthesiacovid-19.org/critical-carepreparation-and-management-in-the-covid-19-pandemic.

2. WHO. Clinical management of severe acute respiratory infection when Novel coronavirus (2019-nCoV) infection is suspected: Interim Guidance. March 13, 2020. Available from: https://www.who.int/docs/defaultsource/coronaviruse/clinical-management-of-novel-cov.pdf. Accessed on Jun 1, 2020.

3. Respiratory Care Committee of Chinese Thoracic S. Expert consensus on preventing nosocomial transmission during respiratory care for critically ill patients infected by 2019 novel coronavirus pneumonia. Zhonghua Jie He He Hu Xi Za Zhi 2020; 43: 288-96.

4. Harari Sa VM, Blasi F, Centanni S, Santus Pa, Tarsia P. Managing the Respiratory care of patients with COVID-19. Italian Thoracic Society -Associazione Italiana Pneumologi Ospedalieri - Societa Italiana Di Pneumologia. March 23, 2020. Available from: https://www.ersnet.org/ covid-19-blog/sharing-italian-recommendations. Assessed on Jun 1, 2020.

5. The Australian and New Zealand Intensive Care Society. COVID-19 Guidelines. Melbourne: ANZICS; 2020. Available from: https://www. anzics.com.au/coronavirus-guidelines/. Accessed on Jun 1, 2020.

6. Kluge S, Janssens U, Welte T, Weber-Carstens S, Marx G, Karagiannidis C. Recommendations for critically ill patients with COVID-19. Med Klin Intensivmed Notfmed 2020; 115: 175-77.

7. Alhazzani W, Moller MH, Arabi Y M, Loeb M, Gong MN, Fan E, et al. Surviving Sepsis Campaign: guidelines on the management of critically ill adults with Coronavirus Disease 2019 (COVID-19). Intensive Care Med 2020; 46: 854-87.

8. Hui DS, Chow BK, Lo T, Tsang OTY, Ko FW, Ng SS, et al. versusExhaled air dispersion during high-flow nasal cannula therapy CPAP different masks. Eur Respir J 2019; 53: 1802339.

9. Kotoda M, Hishiyama S, Mitsui K, Tanikawa T, Morikawa S, Takamino A, et al. Assessment of the potential for pathogen dispersal during highflow nasal therapy. J Hosp Infect 2020; 104: 534-7.

10. Tran K, Cimon K, Severn M, Pessoa-Silva CL, Conly J. Aerosol generating procedures and risk of transmission of acute respiratory infections to healthcare workers: a systematic review. PLoS One 2012; 7: e35797.

11. Rochwerg B, Granton D, Wang DX, Helviz Y, Einav S, Frat JP, et al. High flow nasal cannula compared with conventional oxygen therapy for acute hypoxemic respiratory failure: a systematic review and meta-analysis. Intensive Care Med 2019; 45: 563-72.

How to cite this article: Zhang TT, Dai B, Wang W. Should the highflow nasal oxygen therapy be used or avoided in COVID-19? J TransI Intern Med 2020; 8: 57-8. 